\title{
Recent Developments at IPP on Evaporation and Control of Caesium in Negative Ion Sources
}

\author{
M. Fröschle*, R. Riedl, H. Falter, R. Gutser, U. Fantz and the IPP NNBI team \\ Max-Planck-Institut für Plasmaphysik (IPP), Garching
}

\begin{abstract}
$\underline{\text { Abstract }}$
The neutral beam injection system for ITER requires an ion source based on negative hydrogen and deuterium ions. The production of negative ions relies mainly on the conversion on a cesiated surface with a low work function. The influence of Cs on the work function and the optimal layer thickness is discussed. A list of Cs properties relevant for the ion source is compiled. The Cs oven used at IPP Garching is introduced and its modification with a valve is described, test results are presented. The standard of knowledge at IPP of the Cs dynamics in the plasma source is discussed. With respect to the surface bonding of Cs two methods to control the Cs are presented: the temperature controlled source chamber and the heated plasma grid. The success of coating the inner source walls with molybdenum is mentioned. Further Cs diagnostics applied and explored at IPP are presented.
\end{abstract}

\section{$\underline{\text { Key words }}$}

ITER NNBI, negative ions, caesium, Cs evaporation, Cs oven, Cs control

\section{Introduction}

Plasma sources for negative ions (hydrogen or deuterium) require a mechanism to produce these particles by adding an electron to a neutral or two to the positive ion. In a low temperature plasma (electron temperature $<10 \mathrm{eV}$ ) negative ions are produced in a certain amount in the plasma itself ("volume production") however the amount of particles converted at a surface ("surface production") is much higher at the required pressure of $0.3 \mathrm{~Pa}$. As the survival length of negative ions in the source is very short - in the range of below one to a few $\mathrm{cm}$ - particles 
which are born near an extraction aperture have a much higher extraction probability [1]. Therefore the plasma grid and there especially the surfaces in direct neighbourhood to the apertures are very important for a high negative ion yield.

The effectiveness of the surface production correlates with a low work function of the specific surface. A low work function can be achieved with a thin Cs layer on metal surfaces [2]. The optimal layer thickness is about 0.5 - 1 monolayer, which are $2.4-4.8 \times 10^{14}$ atoms per $\mathrm{cm}^{2}$. In Figure 1 the work function against Cs deposition is shown for Cs on pure tungsten and for Cs on hydrogen covered tungsten [3]. With a layer thickness of 0.6 monolayer on tungsten the work function can be reduced to $1.45 \mathrm{eV}$ [4]. Hydrogen particles, plasma or UV light might help to

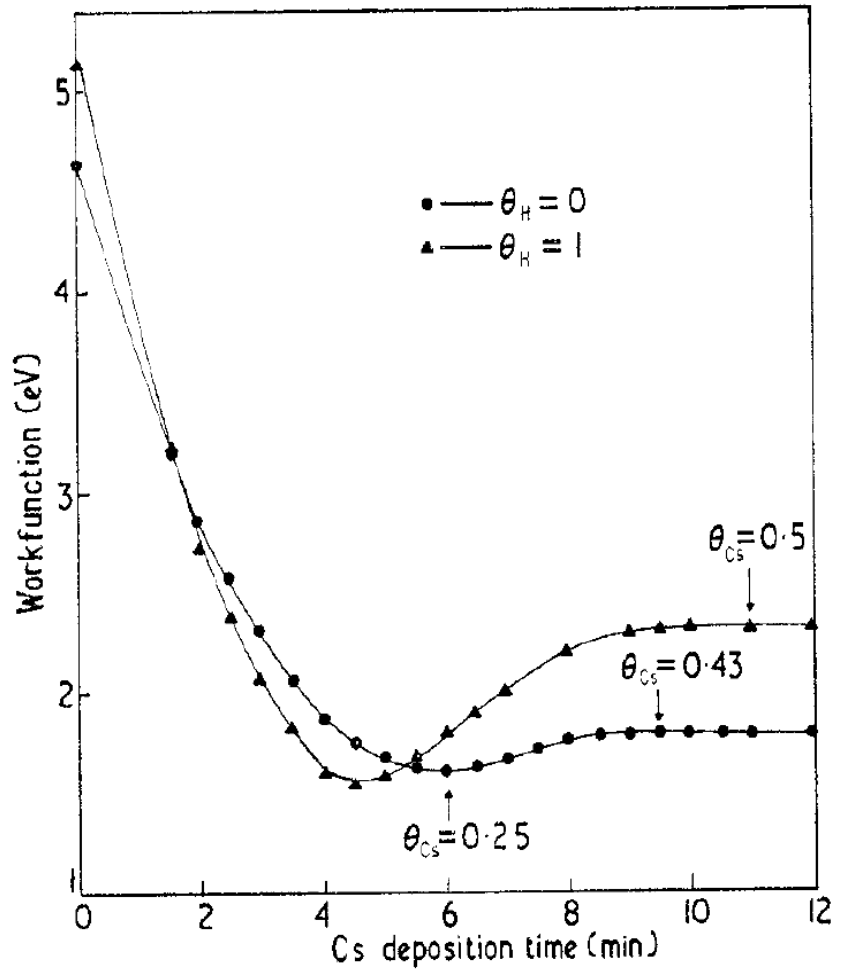
reduce the work function additionally. However it is not clear to what extend these values can be achieved, since the ultrahigh vacuum and the ultraclean metal surfaces with orientated crystals are not obtainable in negative ion sources. In addition, plasma operation influences the Cs layer and multifarious impurities such as Cs compounds or sputtered wall materials contaminate the surfaces. In experiments at University of Augsburg stable work function values of 2.7 $3.0 \mathrm{eV}$ have been found under conditions which are typical for negative ion sources but on a unheated $\mathrm{Cu}$ probe [5].

Figure 1: Work function curves of Cs on W(100) and Cs on H-covered W(100) [3]

Good Cs conditions not only enhance the yield of negative ions but also reduce - even more drastically - the amount of (co extracted) electrons. All this might illustrate the necessity of a precise control of the Cs layer on the plasma grid of negative ion sources. 


\section{Physical and chemical properties of caesium}

Caesium is the heaviest stable alkali-metal with the largest atomic radius. Therefore it has a strong affinity to dispose its outmost electron, which is the reason for its powerful electropositivity and low work function.

It reacts strongly with many other elements, almost solely into ionic compounds. Table 1 sums up the main compounds with hydrogen and the elements of air. $\mathrm{CsOH}$ is the strongest water soluble base. [6][7][8])

\begin{tabular}{|c|c|c|c|}
\hline Formula & Name & Colour & Melting point \\
\hline $\mathrm{CsH}$ & caesium hydride & white & $\begin{array}{c}170^{\circ} \mathrm{C} \\
\text { (decomposes) }\end{array}$ \\
\hline $\mathrm{Cs}_{2} \mathrm{O}$ & dicaesium oxide & yellow to orange & $490^{\circ} \mathrm{C}$ \\
\hline $\mathrm{CsO}_{2}$ & caesium superoxide & yellow to orange & $600^{\circ} \mathrm{C} / 432^{\circ} \mathrm{C}$ \\
\hline $\mathrm{Cs}_{2} \mathrm{O}_{2}$ & dicaesium peroxide & yellow & $590^{\circ} \mathrm{C}$ \\
\hline $\mathrm{CsNO}_{3}$ & caesium nitrate & white & $414^{\circ} \mathrm{C}$ \\
\hline $\mathrm{Cs}_{2} \mathrm{CO}_{3}$ & caesium carbonate & white & $610^{\circ} \mathrm{C}$ \\
\hline $\mathrm{CsOH}$ & caesium hydroxide & colourless & $272^{\circ} \mathrm{C}$ \\
\hline
\end{tabular}

Table 1: Ionic compounds of Cs with hydrogen and the elements of air: chemical formulas, colors and melting points [6][7][8].

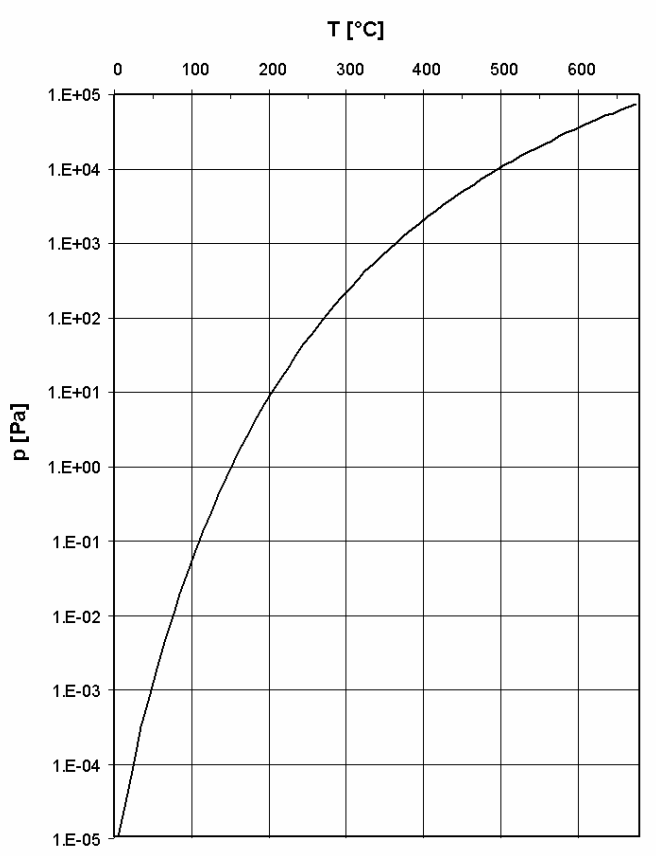

Pure caesium melts at $28.45^{\circ} \mathrm{C}$ and has a heat of fusion of $2092 \mathrm{~J} / \mathrm{mol}$. The boiling point is at $671^{\circ} \mathrm{C}$.

The vapour pressure of caesium has a steep dependence of the temperature in the relevant range from $20^{\circ} \mathrm{C}$ to $250^{\circ} \mathrm{C}$. A graph of the vapour pressure of Cs calculated with the formula of Taylor/Langmuir [9] is shown in Figure 2.

Figure 2: Vapour pressure of Cs against temperature, calculated with the formula given in [9]. 
The surface tension of caesium $\left(6.24 \times 10^{-4} \mathrm{~N} / \mathrm{m}\right.$ at $\left.152^{\circ} \mathrm{C}[10]\right)$ is comparable to the one of water (at $80^{\circ} \mathrm{C}$ ). But caesium has a very poor wettability on (usual) metal surfaces [11]. Figure 3 shows scanning electron microscope records of cesiated copper probes, obtained in a small laboratory plasma source at University of Augsburg. It can be seen that Cs conglomerates on the surface: on the left side of the picture in form of drops, on the right side - where a higher amount of Cs was deposited and plasma was on - crystallized in form of frost patterns. The surface tension must be quite more effective than the adhesion on the metal or - probably more exact than the adhesion on the first Cs dipole layer (see chapter 5). The character that can be seen on the right picture might additionally be formed by strong shrinking: with $9.4 \times 10^{-4} \mathrm{~K}^{-1}$ caesium is the element with the largest thermal expansion, almost a 100 times higher than steel.
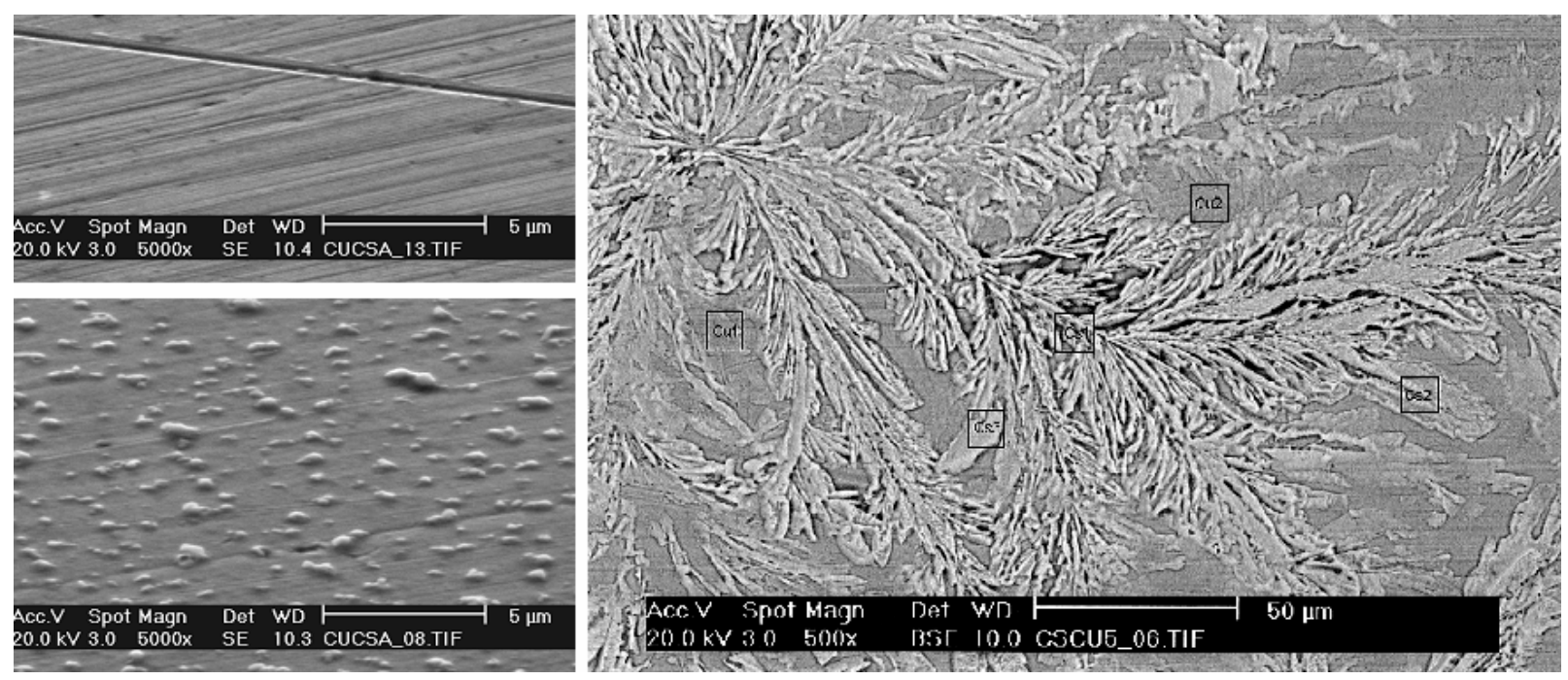

Figure 3: Scanning electron microscope (SEM) records of the surface of cesiated Cu-probes. On the left figure a probe before (top) and after (bottom) Cs evaporation (with a dispenser, no plasma) is shown. On the right side the Cs (probably CsOH) is obviously crystallized (Cs oven, after plasma). The figures illustrate the poor wettability and the weak surface bonding of Cs on metal surfaces. But also in the blank regions a small amount of Cs was indicated (by EDX, energy dispersive x-ray spectroscopy). All probes have been exposed to air before the SEM record. 


\section{Caesium ovens used at IPP Garching}

At IPP Garching several concepts of Cs ovens were realized. At the beginning Cs evaporation was done by heated Cs pellets. Than an oven was designed with a reservoir for liquid Cs, filled in a glove box. This oven had a bellow which enabled to draw back the evaporation spout behind a shutter. But the diaphragm bellow could not be cleaned sufficiently during revision and corrosion caused a leak.

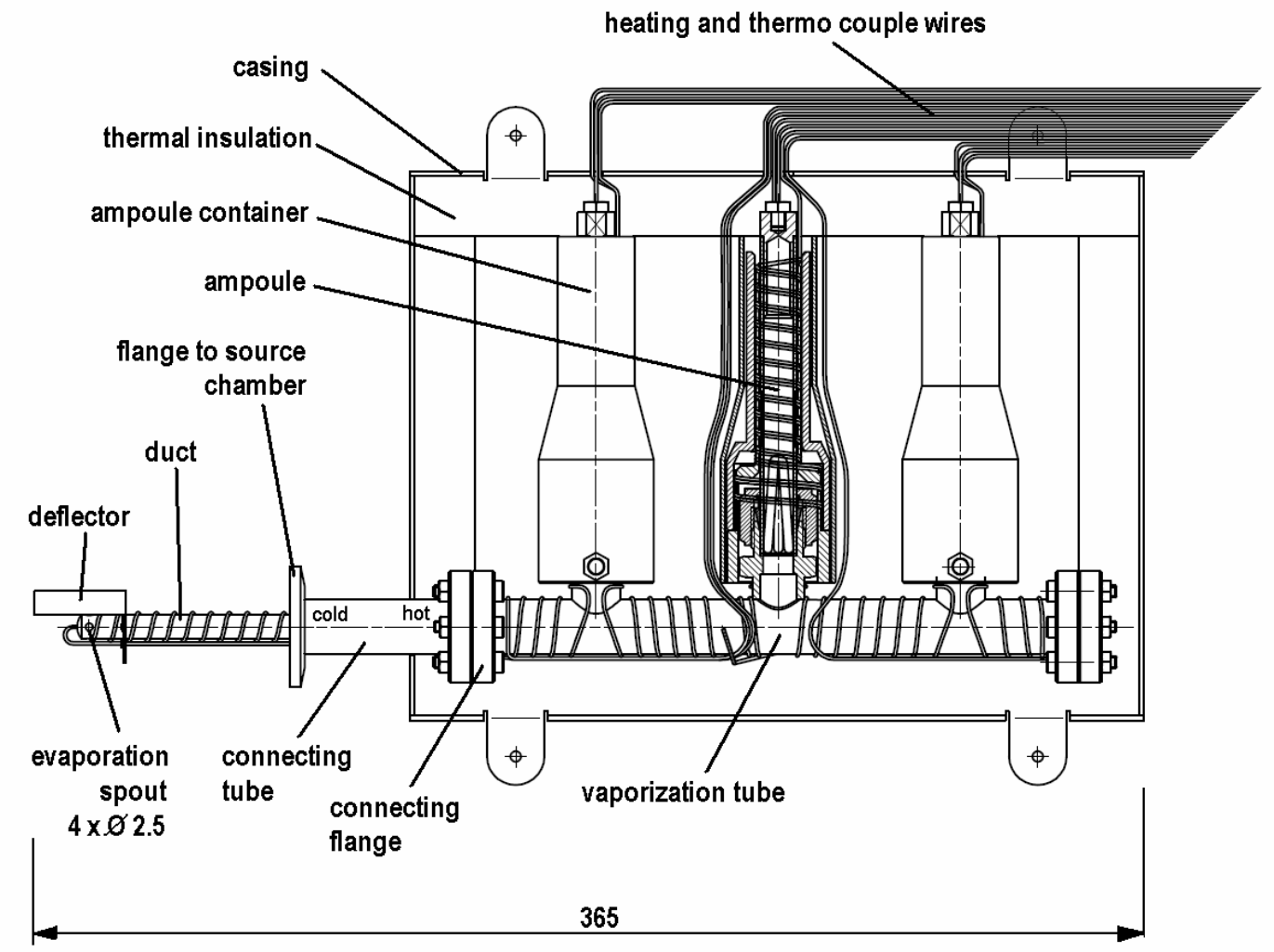

Figure 4: Cs oven commonly used at IPP Garching. Original design: J. Steinberger, IPP.

A layout of the currently applied oven is shown in Figure 4. This oven has three ampoule containers, each with an $1 \mathrm{~g}$ ampoule of Cs. When the oven is attached to the source, evacuated and heated up to a moderate temperature $\left(\sim 40^{\circ} \mathrm{C}\right)$ an ampoule can be cracked from outside. The Cs passes into the vaporization tube, where the liquid Cs is stored. Through the duct and the evaporation spout the Cs vapour flows into the plasma chamber. These ovens have 5 separate 
temperature control circuits (one for each ampoule container, one for the vaporization tube and one for the duct). The oven is encased by a thermal insulation and a case of aluminium. The vaporization tube is meant to control the vapour pressure and therefore has to be the coldest part of the oven. The other parts are kept to higher temperatures, typically $20^{\circ} \mathrm{C}$ to $60^{\circ} \mathrm{C}$ above.

Since years these ovens are working satisfactorily at IPP. But it was observed, that the evaporation rate was smaller than predicted by the temperature of the vaporization tube and the corresponding vapour pressure. On the other hand "caesium bursts" happened sometimes, in which huge amounts of Cs were released into the source within a short time. Recently it has been identified, that via the connection tube (see Figure 4) that couples the oven onto the source, too much heat is lost, causing the connecting flange being the coldest part of the oven and thus determining the vapour pressure. Liquid Cs condenses at the inner surface of the flange and presumably blocks the duct ( $66 \mathrm{~mm})$. By the pressure in the oven it could be pushed forward and reaching the hot duct it would vaporize quickly, causing the burst.

\section{Development and performance of a Cs oven with a valve}

At the IPP long pulse experiment "MANITU" was a demand for a fast and more precise Cs evaporation. For this purpose the concept of the common IPP Cs oven was modified by introducing a valve at the end of the vaporization tube as shown Figure 5. The valve is closed by a spring (11.4 $\mathrm{N}$ closing force) and can be opened by an electro magnet, the coil attached from outside. The sealing itself was made of metal, a copper ball end onto a stainless steel surface was chosen and the partners were grinded in. By a stroke of $3.5 \mathrm{~mm}$ the guidance is done directly at the ball end (in open position at its outer diameter, at closed position on the sealing surface itself). This arrangement gave the valve a good tightness.

Since Cs can flow behind the yoke, the tube inside the electro magnet had to be temperature controlled as well. But also the coil - the nominal power is $30 \mathrm{~W}$ - must not overheat. To achieve both, the coil is equipped with cooling ribs and a high temperature insulation is inserted between the tube and the coil. To ensure the valve position, feedback is given by permanent magnets which reach through the partition wall and move a micro switch. 


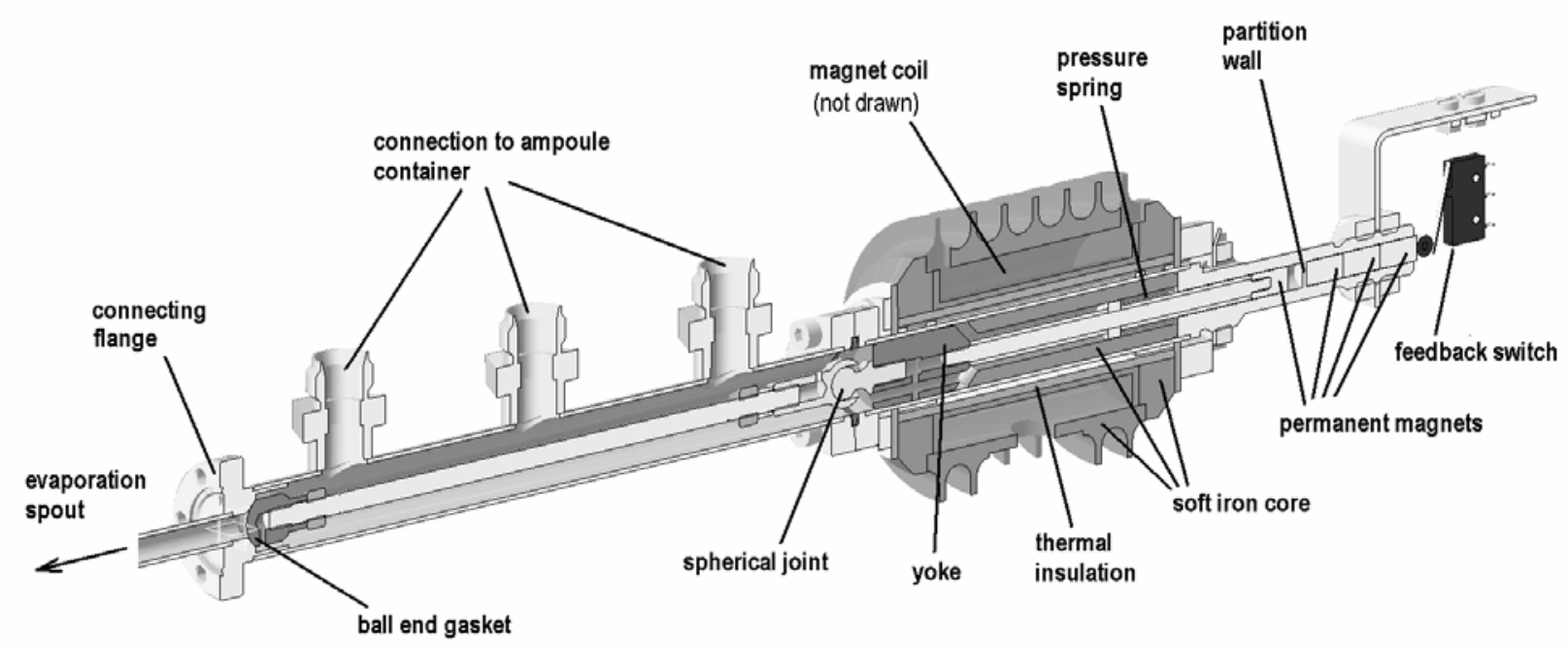

Figure 5: Longitudinal section across the main parts of the Cs oven with valve.

An additional temperature control circuit for the connecting flange was installed and the oven was tested in the laboratory plasma source at University of Augsburg. The Cs flow was measured by a surface ionization detector (SID, see chapter 6). Figure 6 shows a graph of the

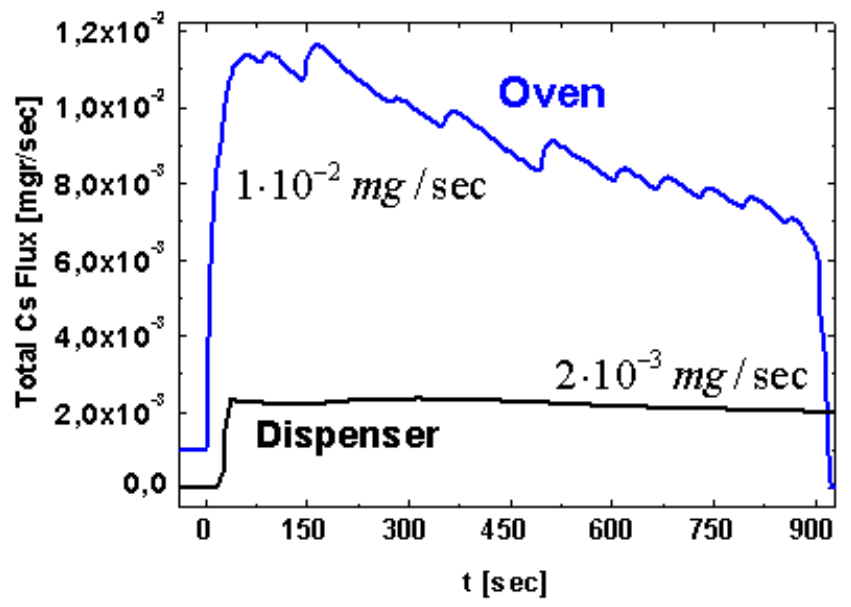

Figure 6: Total Cs flux of the oven measured with a SID and calibrated with the signal of a Cs dispenser. The ripple in the signal correlates with oscillations in the temperature control circuit, the falling of the signal with an over all reduction of the vaporization tube temperature from $180^{\circ} \mathrm{C}$ to $176^{\circ} \mathrm{C}$. total Cs flux of the oven against time.

At a temperature of the vaporization tube of $180^{\circ} \mathrm{C}$ the Cs flux is ca. 11 $\mu \mathrm{g} / \mathrm{s}$. During the pulse, the indicated temperature decreased from $180^{\circ}$ to $176^{\circ} \mathrm{C}$ and so did the Cs flux, it was reduced from $11 \mu \mathrm{g} / \mathrm{s}$ to roughly 8 $\mu \mathrm{g} / \mathrm{s}$. The ripple on the signal correlates with the observed oscillations of the temperature control circuit. Both phenomena illustrate the strong dependency of the Cs flux to the temperature of the oven: the vapour pressure is rising steeply with 
temperature and in addition the flux seems to correlate almost with the vapour pressure per square. E.g. for $20^{\circ} \mathrm{C}$ higher temperature $\left(200^{\circ} \mathrm{C}\right)$ a more than fourfold flux was measured, whereas the vapour pressure rises 2.2 times. This observation however is not conform with an analytical calculation over the flow path, which predicts only a slight more than linear dependency because of the flow being in the molecular and Knudsen range.

In addition it has been observed that the measured Cs flux within the same set temperatures still varies much. The reason for this is yet not clear but it is suspected, that the thermocouples which are only clamped to the oven have insufficient contact and therefore do not measure accurately enough. Another problem of this oven is that the valve is jammed sometimes and can only be released by a high coil current. During revision a white deposit was found on the guiding of the yoke, an indication for caesium hydride, which possibly is formed catalytically at the nickel surface of the yoke.

\section{Dynamics and control of Cs in plasma sources for negative ions}

Without plasma, a Cs atom in the volume of the source does only a few collisions since the background pressure is at $10^{-5}$ mbar and is soon hitting the wall where it is immediately adsorbed. Depending on the wall temperature, it is sticking there for hours or days (not taking into account the sputtering by plasma pulses) until it is released again [12]. In other words, much more Cs sticks on the surface than is released into the volume. The influence of the chemical bonding is still not clear. Calculations, which consider the balance of adsorption and thermal desorption only, estimate a much higher loss of Cs (through the apertures) than observed. This indicates a smaller density in the volume and therefore a stronger surface bonding than predicted only from the vapour pressure.

The colder the walls, the more Cs is stored at the surfaces, reducing the amount in the volume. This makes it difficult to establish and retain the optimum layer thickness on the hot surface of the plasma grid (see below). Therefore also the walls of the IPP ion sources are heated and set to a temperature of about $50^{\circ} \mathrm{C}$. It is remarkable that the vapour pressure of (pure) Cs rises within the range from $20^{\circ}$ to $50^{\circ} \mathrm{C}$ by a factor of 17 , which obviously produces good Cs conditions. Thus the negative ion sources act more stable and much less Cs is found on the source walls 
during revision. Even more, the Cs conditioning of the source, which is correlated with high ion and low electron current, can be controlled by the source temperature in some respects.

Within the range of up to one monolayer, Cs has a strong binding energy on metal surfaces as it is ionic and covalently bonded (a sort of ionic enhanced covalent binding) [13]. Above one monolayer Van der Waals forces form a weaker binding. In other words, there is a stable zone within the desired layer thickness, that can be controlled by heating the plasma grid. At IPP the grid temperature is set to $150-200^{\circ} \mathrm{C}$ whereas only a slight difference in performance could be observed within this range of temperature (if the source is well conditioned).

In plasma sources different kinds of impurities appear and a major part of these can be sputtered wall materials. Compared to compact materials with a low work function it is a significant advantage of the technique of Cs evaporation, that the Cs layer can be renewed permanently. Nevertheless at the IPP test bed MANITU, a big step forward towards a reliable, high performance negative ion source was done covering almost all copper surfaces in the driver and source chamber with molybdenum. As this material is hardly sputtered, the sensitive Cs surfaces are less buried. The success was a high and stable performance as well as a reduced Cs consumption [14].

\section{Caesium diagnostics at IPP Garching}

At present Cs monitoring at the IPP test beds is done by optical emission spectroscopy during plasma operation, quantifying the emission line of Cs at $852 \mathrm{~nm}$ [15]. As the intensity depends also on the plasma density and temperature, this value is normalized to the $\mathrm{H} \beta$ emission. This quotient quantifies the free Cs in the source during a plasma pulse and therefore is a good indication also for the overall cesiation of the source. The correlation between this signal and the actual source performance however is very complex.

Experimental observation show, that the Cs density in the gas phase (plasma off) affects the conditions on the plasma grid much more, making its measurement highly desirable. First tests with a surface ionization detector (SID) [16][17] are carried out currently. The principle of this sensor is shown in Figure 7: Cs atoms which hit the hot grid ( 1000 K) are ionized and drawn by 
a bias voltage $(50 \mathrm{~V})$ onto the ion collector. The current between grid and collector corresponding to the Cs density - is measured by a pico ampere meter (Keithley). The SID was tested and calibrated with Cs dispensers, which are industrial available Cs sources, where the Cs is stored in a getter material and evaporated by a heating current [18]. The range of the measured current was between 10 and a several hundred nA with the dispenser, signals of the Cs oven have been up to $600 \mu \mathrm{A}$ (Figure 6).

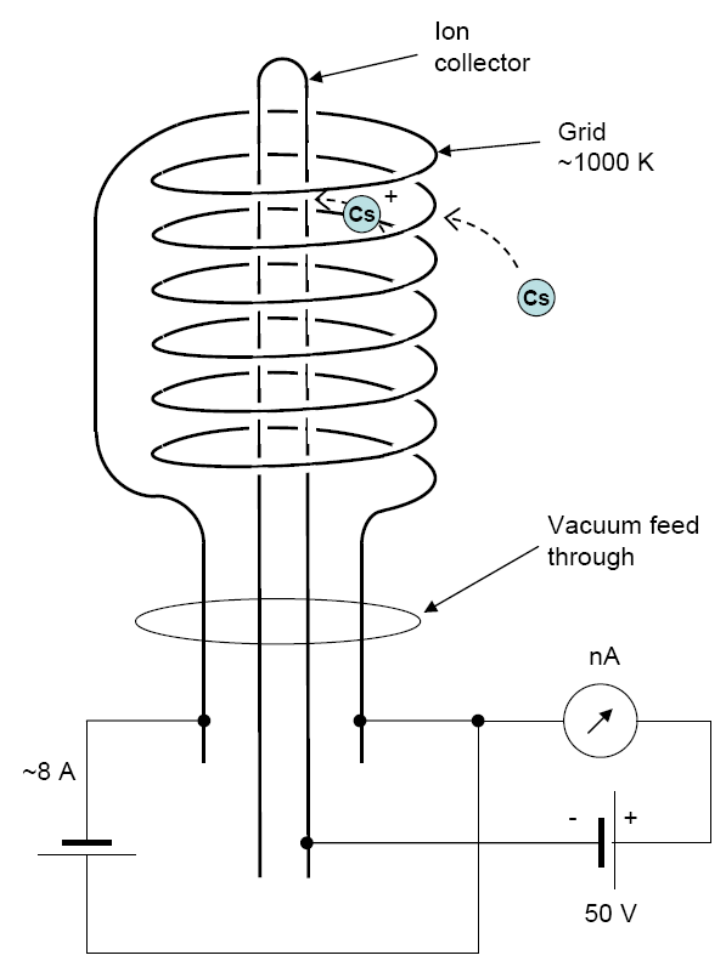

Up to now Bayard-Alpert measuring cells were used as SID, which have only one pin for the ion collector. It was observed, that the signal of the SID drifted, especially after the exposure to high Cs densities. It is supposed, that Cs compounds on the ion collector disturb the measurement. Therefore - as indicated in Figure 7 - a SID was designed with a loop ion collector. Impurities shall be removed heating up the ion collector by a current.

Figure 7: Principle sketch of the surface ionization detector (SID). Cs atoms are ionized on the hot grid and drawn onto the ion collector. $A$ ampere meter measures the current ( $>10 \mathrm{nA}$ ) which corresponds to the Cs density. Here the ion collector is looped to enable cleaning by an heating current.

Other methods of Cs and work function diagnostics are investigated as well. For example a quartz micro balance can be used to measure the amount of Cs on surfaces and a work function measurement should be adopted to the source and plasma operation. Absorption spectroscopy could also quantify the Cs in the gas phase and is desirable for measurements in front of the grid, since the SID must be located more backwards in the source and is therefore dedicated to control the flux of the Cs oven.

In parallel to the diagnostics computational codes for the Cs dynamics are developed at IPP [19]. 


\section{Conclusions}

The desired low work function of the plasma grid of negative ion sources is coupled to a very thin and sensitive Cs layer. At IPP Garching several attempts are ongoing for understanding the Cs dynamics in the sources. A Cs oven with a valve was developed, still being improvable concerning reliable evaporation. Important mechanisms have been found to control the Cs conditions and to enhance the performance of the source. These are in particular the temperature controlled source chamber, the heated plasma grid and covering heat loaded copper surfaces with molybdenum.

\section{Acknowledgements}

Beside the EURATOM association which is supporting our work we especially want to thank the University of Augsburg for the willing to carry out the testing of the Cs oven and the surface ionization detector.

\section{References}

[1] O. Fukumasa, R. Nishida: Modelling of negative ion transport in caesium-seeded volume negative ion sources, Nucl. Fusion 46 (2006) S275-S280

[2] W.G. Graham: Properties of Alkali Metals Adsorbed onto Metal Surfaces; Proc. 2nd int. Symp. on "Production and Neutralization of Negative Hydrogen Ions and Beams, Brookhaven National Laboratory, New York (1980)

[3] C.A. Papageorgopolous, J. Chen: Cs and H2 adsorption on W(100). J. Phys. C: Solid State Phys., Vol. 6, L279 (1973)

[4] J. Pamela 1995: The physics of production, acceleration and neutralization of large negative ion beams, Plasma Phys. Control. Fusion 37 A325-A336

[5] S. König: Analyses of the properties of caesiated surfaces in hydrogen plasmas, IPP Report Nr. $4 / 288$

[6] http://www.webelements.com/compounds/caesium/ 
[7] http://en.wikipedia.org/wiki/Caesium

[8] http://www.chemicalland21.com

[9] J. Bradshaw Taylor, I. Langmuir: Vapor Pressure of Caesium by the Positive Ion Method, Phys. Rev. 51, 753 - 760 (1937)

[10] O. A. Timofeevicheva, V.B. Lazarev: The surface tension of metallic cesium, Russian Chemical Bulletin, Volume 11, Number 2 / February 1962, p. 333 - 334

[11] K. Sato, Y. Kitamura, H. Suzuki, Liquid metal ion source, United States Patent 5194739, www.freepatentsonline.com

[12] D. Wünderlich, R. Gutser, S. Christ-Koch, U. Fantz, M. Berger, P. Franzen, M. Fröschle, B. Heinemann, W. Kraus, C. Martens, P. McNeely, R. Riedl, E. Speth: Modeling of Negative Ion RF Sources for ITER NBI: Current Status and Recent Achievements, EPS conference 2008, to be published

[13] J.D. Levine and E.P. Gyftopoulos: Adsorption physics of metallic surfaces..., Surface Sci. 1 (1964), p. 171.

[14] W. Kraus, M. Berger, H.-D. Falter, U. Fantz, P. Franzen, B. Heinemann, P. McNeely, R. Riedl, E. Speth, A. Stäbler, D. Wünderlich: Development of RF driven H-/D- sources for ITER, EPS conference 2008, to be published

[15] U. Fantz, , H.D. Falter, P. Franzen, M. Bandyopadhyay, B. Heinemann, W. Kraus, P. McNeely, R. Riedl, E. Speth, A. Tanga and R. Wilhelm: Diagnostics of the cesium amount in an RF negative ion source and the correlation with the extracted current density, Fusion Engineering and Design, Volume 74, Issues 1-4, November 2005, Pages 299-303

[16] J.B. Taylor: Eine Methode zur direkten Messung der Intensitätsverteilung in Molekularstrahlen, Zeits. f. Physik 57, 242 (1929)

[17] F. Stienkemeier, M. Wewer, F. Meier, H. O. Lutz: Langmuir-Taylor surface ionization of alkali ..., Rev. Sci. Instrum. 71, 3480 (2000)

[18] SAES Getters S.p.A.: Alkali Metal Dispensers, technical bulletin

[19] R. Gutser et al, Simulations for the generation and extraction of negative hydrogen ions in RF-driven ion sources, Proceedings of the 1st International Conference on Negative Ions, Beams and Sources (NIBS), Sept. 2008, to be published 